\title{
Expressões de poder e de solidariedade em Moçambique e em Angola: observando a inter-relação entre gênero e formas de tratamento
}

\author{
Sabrina Rodrigues Garcia Balsalobre
}

Universidade Estadual Paulista Júlio de Mesquita Filho - Brasil

\section{Palavras iniciais}

A Língua Portuguesa (LP) é herança colonial comum a países como Brasil, Guiné Bissau, Cabo Verde, São Tomé e Príncipe, Moçambique, Angola e Timor Leste. Contudo, para cada um desses povos, essa língua desempenha valores sociosimbólicos peculiares a suas realidades nacionais. Assim sendo, com um intento de se observar a variedade de LP, especificamente a utilizada em Moçambique e em Angola, considerando a inter-relação que há entre fatores de ordem social e linguística, privilegiou-se nesse estudo o sistema de formas de tratamento nominal e pronominal. $\mathrm{O}$ foco desse estudo é, portanto, a observação do comportamento social das pessoas que é expresso por meio de suas escolhas linguísticas. Assim sendo, a intenção é a de observar como mulheres e homens moçambicanos e angolanos se relacionam e expressam suas percepções de mundo por meio da língua, mais especificamente, por meio de suas escolhas tratamentais ${ }^{1}$.

Com esse objetivo, três questionamentos baseiam as análises: 1) Há diferença no comportamento linguístico quando os interagentes relacionam-se com pessoas do mesmo gênero? 2) Ocorre mudança de comportamento linguístico quando os interagentes são de gêneros diferentes? 3) É possível depreender diferenças no comportamento de moçambicanos e de angolanos? A fim de se concretizar essa busca investigativa, tomou-se como pilar teórico a complementaridade existente entre a sociolinguística e a pragmática - resumidamente, a sociopragmática. Além disso, de forma mais específica, está em foco a observação dos ideais semânticos do poder e da solidariedade (Brown; Gilman, 1960/1972), como forças sociais claramente expressas por meio das escolhas linguísticas.

1. Para os efeitos deste estudo, os termos "formas de tratamento", "usos tratamentais" e "formas/termos de endereçamento" são considerados sinônimos. 
Dessa forma, o presente capítulo contará com o seguinte percurso argumentativo: inicialmente, estará em foco uma breve observação sobre as nuances particulares de uso da LP em Moçambique e em Angola; seguirá uma seção de cunho mais teórico, na medida em que visa situar o fenômeno linguístico privilegiado para essa análise, as formas de tratamento nominais e pronominais, à luz da Sociopragmática; ainda contemplando objetivos teóricos, a seção seguinte se proporá a descrever a semântica do poder e da solidariedade tão cara à posterior análise dos dados; com um intento crítico, a seção "Breve observação sociolinguística sobre o gênero/sexo" oferecerá um posicionamento teórico acerca do tema motivador desse estudo; em seguida, haverá uma seção com o objetivo de demonstrar a metodologia aqui utilizada; e, por fim, seguirão dois capítulos analíticos: o primeiro dedicado às formas de tratamento nominais e o segundo às formas pronominais.

\section{Moçambique e Angola: a língua portuguesa em África}

Moçambique e Angola são dois países africanos que compartilham a LP como herança colonial. O primeiro deles é banhado pelo Oceano Índico e conta com onze províncias, cuja capital é Maputo. Já o segundo, Angola, é um país situado na África Ocidental, portanto, semelhantemente ao Brasil, é banhado pelo Oceano Atlântico. O território angolano é de $1.246 .700 \mathrm{Km}^{2}$, distribuídos por suas 19 províncias, tendo Luanda como capital (cf. em destaque os dois países na figura 1).

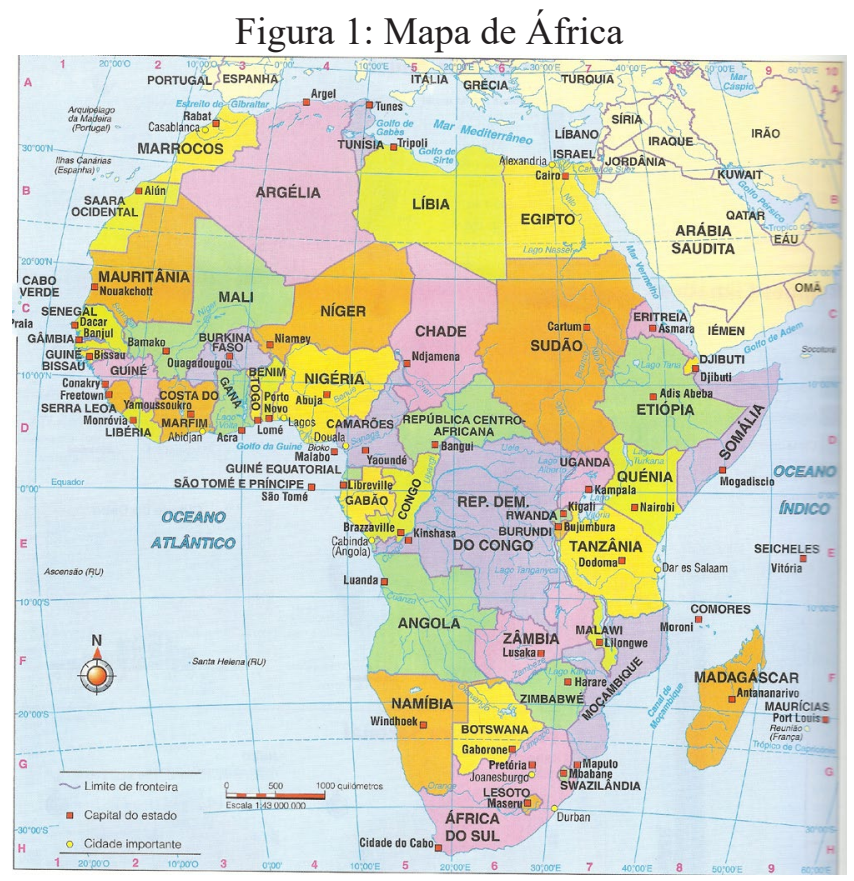

Fonte: Atlas de Moçambique (2009, p.47). 
Para os dois países africanos em questão, a LP possui representatividade nacional $^{2}$, sendo empregada por grande parcela da população em diferentes situações de fala - contudo, convivendo com outros grupos linguísticos. Dessa forma, é possível declarar que se trata de uma língua com diferentes representações simbólicas para essas nações. Acerca disso, Firmino (2006) assevera que a LP, ao passo que adquire novas relações sócio-simbólicas ${ }^{3}$, novos usos e funções - uma nova ideologia, portanto -, inevitavelmente passa por um processo de ser cada vez menos encarada como um elemento intruso e exógeno, para ser vista como algo próprio, que expressa as necessidades e anseios locais. Esse fenômeno é denominado pelo autor como "processo de nativização".

Assim, o português em Moçambique foi se tornando o principal meio de comunicação tanto em situações institucionais como em interações cotidianas nos centros urbanos, pelas ruas, mercados etc. Dessa forma, o número de falantes foi se ampliando e,

à medida que as pessoas usavam o português de diferentes maneiras, ele começou a transcender o seu papel de instrumento político e administrativo para se tornar um veículo de novos tipos de mensagens comunicativas e simbólicas relacionadas com a vitalidade da nova vida nacional de Moçambique (Firmino, 2004, p. 352).

Acerca do cenário de uso da LP em Moçambique, Dias (2002) aponta a formação de três grupos principais: i) há falantes que a usam apenas como língua de contato, para fins comerciais e sociais; ii) há usuários bilíngues ou plurilíngues que se sentem obrigados a usar o português com mais frequência por conta da escola, do trabalho e de contatos sociais frequentes. Esses falantes podem passar a dominar perfeitamente a LP ao longo da vida "ou podem parar em fases diferenciadas de aprendizagem da língua, mantendo em uso uma variedade de língua portuguesa 'diferente"' (Dias, 2002, p. 175); iii) e, finalmente, há um terceiro grupo que usa o português em seu dia a dia de uma forma mais europeizada. Esse cenário é representado pela autora como um 'continuum linguístico', "caracterizado por estágios de fluência que vão desde o monolinguismo na língua bantu,

2. O censo moçambicano de 2007 revelou que $50,8 \%$ da população sabe falar português. Desse total, a maioria dos falantes são homens (60,4\%, em comparação com 42,0\% de falantes mulheres) e está concentrada majoritariamente em zonas urbanas (81,5\% contra 36,6\% em regiões rurais). Por sua vez, o Inquérito do Bem Estar da População (IBEP), realizado pelo Instituto Nacional de Estatística (INE), em 2011, apontou que, de uma amostra de 58.123 pessoas, $82,8 \%$ delas falavam português e $38,6 \%$ possuem esse idioma como língua materna. É válido destacar que, dentre os entrevistados do IBEP, 54,2\% falavam mais de uma língua, podendo ser a portuguesa, línguas angolanas ou estrangeiras.

3. Por relações sócio-simbólicas compreende-se os significados que a língua portuguesa passou a representar nos complexos ambientes linguísticos pós-coloniais, envolvendo as percepções dos povos que passaram a usar essa língua e a consequente avaliação e atitude frente a ela. 
passando por oscilações na competência bilíngue, com etapas de dominância na língua bantu ou na língua portuguesa" (Dias, 2002, p. 177).

Angola, por sua vez, apresenta um cenário linguístico com algumas semelhanças em relação a Moçambique, no sentido de que a LP também divide espaço com línguas autóctones. De acordo com Neto (2012, p. 43), “o português é para os angolanos, simultaneamente, uma língua materna, segunda e estrangeira”. Desde o processo de luta pela independência, a LP era empregada por uma população de assimilados, especialmente em sua capital Luanda, e pelos líderes do MPLA (Movimento Popular de Libertação de Angola) (Fonseca, 2009). Desde então, o português foi se avolumando pelas localidades do país e adquirindo feições cada vez mais autênticas, pertencendo ao universo da música, literatura, burocracia, governança, comércio etc. Entretanto, ao contatar com as línguas locais, o português passou a adquirir características marcadas por novos valores representacionais, hierarquizando grupos e marginalizando falantes não pertencentes à variedade de prestígio.

\section{Formas de tratamento nominais e pronominais: um olhar sócio-prag- mático à língua}

Com o objetivo de se analisar as relações entre a LP e suas representações sociais - mais especificamente nas sociedades moçambicana e angolana - optou-se por privilegiar um recurso do sistema linguístico que expressa a inter-relação entre escolhas linguísticas e motivadores sociais. Com esse propósito, o sistema de formas de tratamento é o fenômeno linguístico investigado por esse estudo.

Em termos gerais, as formas de tratamento são palavras (ou sintagmas) usadas por falantes de uma língua a fim de se dirigir ou de se referir a outra pessoa. Com propósitos didáticos, esse sistema pode ser subdivido em dois macro níveis: (i) Formas pronominais: palavras ou expressões equivalentes aos pronomes de tratamento (você, tu, o senhor, a senhora etc.); (ii) Formas nominais: expressões provenientes de substantivos comuns, nomes próprios, termos de parentesco, profissões etc. São exemplos: amiga, querida, cara, primo, doutor, irmão, chuchu etc.

Quando se analisa uma interação, observa-se que as formas de tratamento - nesse caso específico, as formas de tratamento nominais (doravante, FTN) são mobilizadas no discurso por diferentes razões, fato que garante o seu atributo de plurifuncional. As FTNs, portanto: i) possuem uma função fática, já que asseguram a necessária interpelação entre os membros de uma situação interlocutiva; ii) possuem a característica de organizar a interação, selecionando os alocutários e a gestão dos turnos de fala; iii) são estratégias que marcam o status social dos membros em interação; iv) reforçam a própria relação interlocutiva e o ato de lin- 
guagem. Por essas razões, uma "FTN nunca é relacionalmente neutra" (Kerbrat-Orecchioni, 2011, p.25).

Com essa exposição sobre as FTNs, fica explícito que elas denotam alguma forma de predicação, ainda que seja tênue (Giaufret, 2011). Essa predicação pode ser considerada denominativa por recair sobre um dado pressuposto, ou seja, por se referir a uma denominação já conhecida pelos interlocutores e, na qual, eles se reconhecem (por exemplo: senhor ministro, Paulo). As predicações podem também ser do tipo designativas, uma vez que atribuem uma característica do interlocutor na própria enunciação, ou seja, o locutor predica algo sobre o alocutor (tal como: minha amiga querida).

No que se refere às formas de tratamento pronominais, Neves (2008) afirma que, por serem os pronomes palavras que não contêm um conteúdo descritivo próprio, eles possuem duas grandes funções: uma interacional, já que são os pronomes que representam nos enunciados as pessoas do discurso, permitindo, portanto, que se aponte para elementos situados fora do texto - função dêitica ou exofórica -, e outra textual na medida em que são os pronomes que garantem a continuidade do texto, fazendo referência a elementos já citados no próprio texto - função endofórica, que tem na anáfora a sua principal representante.

À luz da sociolinguística é possível compreender o sistema das formas de tratamento empregado por falantes angolanos e moçambicanos, pelo fato de que esse fenômeno linguístico possui diretamente motivadores sociais. Entretanto, a fim de se debruçar mais a fundo no fenômeno, alguns pesquisadores brasileiros (Lopes, Rumeu, Marcotulio, 2011; Marcotulio, 2010) - baseados na obra de Levinson (1989) - dedicam-se a interpretá-lo também por um viés pragmático, a fim de melhor compreender as razões de seu uso. Vidal (1996) define o fazer pragmático afirmando que se trata de um estudo dos "princípios que regulam o uso da língua na comunicação" (VidaL, 1996, p.13). Mais especificamente, a autora prevê o olhar sobre um falante concreto, que emite um enunciado concreto, envolvido em uma situação comunicativa concreta. Além disso, é também foco da pragmática uma atenção à forma como o destinatário interpretará esse enunciado. Em suma, portanto, a pragmática é

\footnotetext{
uma disciplina que leva em conta os fatores extralinguísticos que determinam o uso da língua, precisamente aqueles que um estudo puramente gramatical não pode fazer referência: noções como as de emissor, destinatário, interação comunicativa, contexto verbal, situação ou conhecimento de mundo serão cruciais (Vidal, 1996, p.14, tradução nossa, grifos da autora) ${ }^{4}$.
}

4. "La pragmática es, por tanto, una disciplina que toma en consideración los factores extralinguísticos que determinan el uso del lenguaje, precisamente todos aquellos factores a los que no pude hacer referencia un estudio puramente gramatical: nociones como las de emisor, destinatario, intención comunicativa, contexto verbal, situación o conocimiento del mundo van a resultar de capital importancia” (p.14). 
Por se conceber que a língua constitui-se tanto em um meio pelo qual as intenções dos falantes são veiculadas, como uma forma de se garantir a interação entre as pessoas, Vidal (1996) associa a pragmática a uma vertente social da comunicação. Nesse sentido, é possível estabelecer cruzamentos entre essa perspectiva linguística e a sociolinguística. Nas palavras de Levinson (2007):

Efetivamente, a pragmática e a sociolinguística compartilham muitas áreas de interesse comum, e a sociolinguística tem contribuído muito para certas áreas da pragmática, especialmente o estudo da dêixis social e os atos de fala e seu uso. Todavia, a pragmática, por sua vez, tem muito a contribuir para a sociolinguística; pois, ao tentar entender a importância social dos padrões de uso da linguagem, é essencial compreender as propriedades e os processos estruturais subjacentes que criam exigências à interação verbal (Levinson, 2007, p.481).

\section{3. $O$ poder e a solidariedade em foco}

Em 1960, Brown e Gilman lançaram o artigo que inaugurou uma nova tendência no estudo das formas de tratamento: "The pronouns of power and solidarity". Os autores, naquele momento, propuseram um modelo que envolve o uso dos tratamentos correspondentes às duas características principais das sociedades: 0 poder e a solidariedade. Para estabelecer esse padrão semântico, os autores analisaram a covariação entre a forma de tratamento empregada e o relacionamento objetivo existente entre o falante e o interlocutor ao qual ele se dirige.

Para Brown e Gilman (1972), poder é o relacionamento não recíproco que se estabelece entre, no mínimo, duas pessoas, no sentido de que elas não podem ter poder na mesma área de comportamento. Dessa forma, o poder semântico revela formas de tratamento típicas da relação entre um superior e um inferior, demonstrando que existe contextualmente uma estrutura social que define hierarquias entre indivíduos. Essa hierarquização pode ter diferentes bases de acordo com os valores sociais vigentes, que vão desde a força física, a riqueza, a idade e o sexo, até os papéis institucionalizados no estado, na igreja, no exército e dentro da família. Assim, a primeira experiência de subordinação de um indivíduo ao poder acontece no seio de sua própria família, na relação reverencial com seus pais. Posteriormente, a norma vigente que prevê o tratamento assimétrico é transferida para as demais relações sociais, como a que se estabelecesse entre patrão e empregado, por exemplo.

Em contrapartida, Brown e Gilman (1972) apontam a existência de relações interpessoais estabelecidas a partir de um padrão de reciprocidade. Esse tipo de relação revela uma maior complexidade, se comparada às relações de poder, pelo fato de que a maior probabilidade de ocorrer uma relação simétrica, no sentido mais estrito da palavra, se dá no tratamento que dois irmãos gêmeos podem empregar 
mutuamente ou com um homem conversando e atribuindo um tratamento para si mesmo.

Apesar da dificuldade de se estabelecer relações em que não haja nenhuma denotação de poder, os autores preveem que pode haver relações menos assimétricas entre pessoas que frequentam a mesma escola, que compartilham da mesma profissão, ou demais atividades diárias. Há, ainda, a possibilidade de se estabelecer relações solidárias pela frequência do contato entre duas pessoas ou a partir de similaridades objetivas. Entretanto, a frequência do contato não faz com que, necessariamente, essas pessoas passem a empregar os tratamentos considerados solidários - isso só ocorre após o estabelecimento de uma relação mais íntima, a partir de uma confluência de opiniões, que resultou desse contato.

\section{Breve observação sociolinguística sobre o gênero/sexo}

Maria da conceição Paiva, em "A variável gênero/sexo", inicia seu capítulo com o seguinte questionamento: "Homens e mulheres falam diferente?" (Paiva, 2013, p.34). A seguir, buscando um pouco mais de especificidade em sua pergunta em função de propósitos sociolinguísticos, propõe outra questão: "Em que limite e de que forma fenômenos linguísticos variáveis estão correlacionados ao gênero/sexo do falante?" (Paiva, 2013, p.34). Fundamentalmente, a preocupação levantada por Paiva (2013) e por diversos outros sociolinguistas contemporâneos é proveniente de Labov (2008). Ao investigar o papel que homens e mulheres desempenhavam na mudança linguística, o autor estabeleceu a seguinte generalização: “(...) a diferenciação sexual da fala frequentemente desempenha um papel importante no mecanismo de evolução linguística" (Ibid. p.348). E o autor continua: "A diferenciação sexual dos falantes não é, portanto, somente um produto de fatores físicos, ou de diferentes quantidades de informação referencial fornecida por eles, mas, sim, uma postura expressiva que é socialmente mais apropriada para um sexo do que para outro" (ibid. p.348-349).

Considerando esse postulado, pesquisadores diversos têm investigado a correlação existente entre fenômenos linguísticos e a variável estratificada sexo. É importante considerar, nesse momento, que, apesar de tradicionalmente ser considerado o "sexo" do falante como variável linguística, para os efeitos dessa pesquisa, utiliza-se o conceito de "gênero", por se avaliar que ele melhor representa a questão do feminino e do masculino como construção social e não biológica/ orgânica. Nesse sentido, entende-se que as sociedades/culturas definem o que consideram um comportamento linguístico mais adequado às mulheres e aos homens. Linguisticamente, essa consideração é relevante, uma vez que, comumente, ouvem-se expressões como "não fica bem para uma garota falar assim". 
Observa-se, contudo, que ocidentalmente há uma tendência de que os comportamentos linguísticos de mulheres e de homens jovens caminhem em direções similares, em função da amplitude de papeis que as mulheres passaram a desempenhar nas sociedades 5 .

A fim de responder a seus questionamentos, Paiva (2013) afirma que as diferenças linguísticas mais visíveis da fala de mulheres e de homens estão focalizadas no plano lexical, mas a autora recorre a diferentes pesquisas linguísticas que comprovam haver influência do gênero também em outros níveis, como o fonológico e o morfossintático, por exemplo. A fim de exemplificar a interferência do gênero no plano discursivo, a autora remete-se a uma pesquisa de Paredes e Silva (1996), acerca da alternância entre as formas de tratamento tu/você na cidade do Rio de Janeiro. De acordo com a pesquisadora, a variável $t u$ sem concordância com o verbo, como ocorre em "Tu quer uma cerveja", ocorre mais frequentemente "na fala de homens (peso relativo .57) do que na fala de mulheres (peso relativo de .43)" (Paiva, 2013, p.35). Esse e outros estudos, portanto, demonstram uma tendência de que exista "uma maior consciência feminina do status social das formas linguísticas” (Paiva, 2013, p.35).

\section{Procedimentos metodológicos: fotografias motivadoras de diálogo}

Com o propósito de se levar a cabo esta investigação, fez-se necessário entrevistar falantes moçambicanos e angolanos acerca de seus usos tratamentais. Com esse intento, empregou-se uma metodologia bastante utilizada por pesquisadores brasileiros de formas de tratamento nos anos 1980 (Mundin, 1981; Abreu; Mercer, 1988): fotografias de perfis sociais são utilizadas para simular diálogos que favorecem o aparecimento das formas de tratamento. Todos os falantes dos dois países foram submetidos aos mesmos procedimentos metodológicos, compondo um corpus linguístico bastante homogêneo. Assim sendo, durante os meses de fevereiro a maio de 2013, realizaram-se entrevistas com 25 pessoas da cidade de Maputo (Moçambique); e durante os meses de junho e julho ocorreram outras 25 entrevistas com angolanos residentes na cidade de Luanda. É preciso salientar que as cidades de Maputo e Luanda ${ }^{6}$ foram, a priori, privilegiadas por contarem com características semelhantes: as duas representam as cidades com maior densidade populacional de

5. Trata-se de uma observação de caráter pessoal, que carece de constatações. Por isso, esse tema será alvo de investigações futuras a fim de se ampliar a compreensão de gênero e sua inter-relação com escolhas tratamentais.

6. É preciso estabelecer a ressalva de que, todas as vezes que houver referência ao português moçambicano, na verdade, está a ser considerada a variedade linguística utilizada na cidade de Maputo (onde os inquéritos aconteceram). De modo idêntico, por português angolano, deve-se considerar a variedade de língua portuguesa falada na cidade de Luanda. 
seus países e todas elas possuem um fluxo muito grande de pessoas oriundas de todas as demais regiões do país, em busca de melhores condições de vida.

A etapa inicial de todas as entrevistas foi a aplicação de um questionário socioeconômico, a fim de se obterem informações de ordem estratificada - tais como idade e escolaridade - e informações não estratificadas, como origem, exposição à mídia, proficiência em uma segunda língua etc. Na sequência, realizava-se a entrevista utilizando as imagens. É importante destacar que as fotografias representativas dos perfis sociais de cada um dos países foram retiradas da internet, para garantir o seu estatuto de publicização e evitar constrangimentos no que se refere aos direitos de imagem.

Nessa etapa, fornecia-se a instrução ao informante de que todas as pessoas fotografadas eram para ele desconhecidas e que as encontraria na rua, em estabelecimentos comerciais ou instituições públicas - procedimento adotado a partir das descrições metodológicas de Mundin (1981). A proposta feita aos entrevistados era que lhes seria indicada, para cada imagem, uma instrução específica contendo um pedido acerca de endereço, referência a uma pessoa que se está procurando, o preço de determinado produto etc. Tendo compreendido a instrução, o informante estabelecia um diálogo com a pessoa da fotografia. Em geral, a grande maioria dos informantes compreendia prontamente a proposta da entrevista e produzia naturalmente diversas formas de tratamento. A fim de que essa metodologia fique mais clara, um exemplo será oferecido a seguir:

(01) "Informante: Avô. Aí tem que ser, tem que chamar mesmo avô. O avô não conhece a Amélia? Onde é que é a casa dela? Eles como conhecem todo mundo do bairro.

\section{Pesquisadora: (Então!)}

I: Normalmente esses mesmo chamamos de avô.

P: (É? Outra coisa não?)

I: Porque às vezes quando chama de senhor acho que, sei lá. Porque às vezes tenho a impressão... ele assim tem a impressão que o senhor é um bocadinho mais jovem. Ele já... a tendência mesmo é chamar avô.

P: (Tá.)

I: Avô. Eu mesmo posso chamar avô. Sem problema.

P: (É? Tá perfeito. Gostei.)"

6. Formas de tratamento nominais: perscrutando as estratégias interativas de mulheres e de homens

Ao se considerar que existe uma significativa diferença no comportamento 
linguístico de mulheres e de homens - asseverada por Labov (2008) e reiterada por pesquisadores brasileiros como Paiva (2013) -, essa seção se propõe a verificar as semelhanças e as diferenças que ocorrem nas escolhas linguísticas de FTNs em função do gênero do entrevistado, comparando-se moçambicanos e angolanos.

Inicialmente, é imperioso reconhecer que os entrevistados dos dois países se mostraram bastante sensíveis ao gênero do perfil social que lhes era mostrado por meio das fotografias. Assim sendo, a identificação do gênero do perfil mostrou-se como um fator motivador preponderante das escolhas de FTNs. Particularmente, as mulheres entrevistadas revelaram-se sensíveis ao fator gênero, sobretudo aquelas com idade superior aos 50 anos. A fim de ilustrar a forma como o gênero do perfil - no caso, o masculino - interferiu nas escolhas linguísticas de mulheres na faixa etária em questão, seguem dois depoimentos de mulheres moçambicanas, uma de 52 e outra de 54 anos, respetivamente. De acordo com uma delas, é possível estabelecer relações solidárias com mulheres desconhecidas - até mesmo atribuir a FTN "amiga". No entanto, na situação hipotética de se relacionar com um homem desconhecido na rua, imediatamente seria necessário adequar o repertório de endereçamento para "senhor". A outra informante, ao final da entrevista, faz uma reflexão geral acerca da sua mudança de posicionamento em relação aos perfis masculinos e femininos. Seguem os excertos ${ }^{7}$ :

(02) "Então, pronto, ih. Ya, mas ela tá ali a vender e eu chego e, boa tarde. Muitas das vezes,

aquelas senhoras ali da rua, eu trato por amigas.

(Ah!)

Eu chego lá: amiga, quanto é que é esse seu tomate aí? Ela vai me dizer quanto é que é. Eu chego ali: boa tarde, amiga. Hãn?

(Aí ela vai dizer dez conto.)

Sim. Ela vai dizer, eu: xii, amiga, tá muito caro esse seu tomate. Não dá pra tirares um bocadinho? Aí eu ainda fico ali a dialogar com elas um pouco. Como são senhoras já. Mesmo essas senhoras que vendem alface, não sei quê. Tem uma amiga aqui que, depois acabamos sendo amigas. Quando eu vou pra lá, mesmo que eu não tenha dinheiro, ela dá. Nem, nem sabe onde é que eu vivo. Pronto, vou pra ali: amiga, não sei quê seu tomatinho, ele tá, pois olha lá, este aqui tá um pouco estragado. Troca lá. Amiga, então pronto, ela acabou por simpatizar. Tem uma outra ali que vende a maçaroca e eu gosto muito de maçaroca.

7. Em 02, a informante de 52 anos simula um diálogo com o perfil representado pela figura de uma vendedora de tomates 


\section{(Ahan.)}

Eu chego lá, se não tenho dinheiro, levo. Depois vou lá pagar-lhe.

(Pronto.)

Ela não sabe onde é que eu vivo. Pronto, porque estabeleceu-se aquela relação de amizade ali ocasional. Pronto. Ya.

(Ah, que legal! Amiga, então!)

Amiga!

(Adorei. Poxa, mas e se passar um, e se for um, um, um vendedor, um homem de fruta, vai ser amigo?)

Ih, aí... eu geralmente faço isso quando são senhoras. Ya. Quando são senhores eu chego lá: boa tarde. Quanto é que custa isso? Ele vai me dizer quanto é que custa. Se esta caro: ih, senhor, tá muito caro. Vê lá se abaixa um pouco o preço." $(\mathrm{MO})^{8}$

(03) "Ya... eu descobri uma coisa sobre mim hoje, ok. É que eu não sinto-me, ah, amedrontada pelas interpretações, má interpretação das mulheres. Mas sinto-me amedrontada pelas más interpretações dos homens. Descobri isso agora, ok, Sabrina. Uma mulher, uma rapariga, eu sei que ela vai entender-me, não vai interpretar mal. E muitos dos rapazes que nós aqui, os rapazes que tavam a vender o crédito pra pra o celular, eu sei que aquilo que me faz dizer senhor é que eles não pensem que eu tô a destratá-los, ok.

(Sim. Perfeito.)

É por aí. É por aí. Mas é mais uma coisa que eu tô a descobrir sobre mim, porque eu sei que é um problema de gênero.

(É?)

Isso eu já sabia, mas agora eu não sabia que no contacto eu também fazia esta distinção.

Nice!" (MO)

Conforme explicitado por esses dois excertos, as entrevistadas - ao avaliarem o perfil da pessoa com quem simularão o diálogo - optam por formas nominais solidárias ao dirigirem-se a outras mulheres, mas preferem tratamentos que demonstram distanciamento a perfis masculinos. Hipotetiza-se, nesse contexto, tratar-se tanto de uma estratégia de preservação da face, quanto de um construto social que determina a diferenciação cultural referente aos papeis sociais de mulheres e de homens. Entretanto, ao se considerar mulheres moçambicanas e

8. Após os excertos das entrevistas, aparecerá entre parênteses duas siglas: "MO" para indicar que o entrevistado é moçambicano e "AN" para indicar que é angolano. 
angolanas mais jovens, particularmente identificadas com padrões mais progressistas, em função de terem curso superior e de ocuparem uma posição de prestígio no mercado de trabalho, as escolhas linguísticas apresentam-se diferentes. Essas mulheres optaram por FTNs mais solidárias ao dirigirem-se a perfis masculinos, tal como mostram os excertos a seguir, produzidos por moçambicanas de 29, 26 e 27 anos e por uma angolana de 19 anos, respectivamente:

(04) “Aí eu ia dizer, né: oi, rasta, me ajuda aí? Como é que eu entro, como é que eu chego na Amilcar Cabral? Ou então eu ia dizer: $b r a d a^{9}$, ajuda aí! Brada ou rasta.

\section{(Amigo?)}

Talvez. Ei, meu amigo, pode me mostrar como é que eu chego lá? Ou, então rasta. Na África do Sul um senhor como este, como eu já tive muitos amigos rastas, eu havia de dizer assim: oi, brada, please, me ajuda aí." (MO)

(05) "Dá pra ver que ele tem mais ou menos a mesma idade que eu. Não é muito mais velho e também não é muito mais novo. Então, eu ia dizer: mano, faz favor, sabes onde é que é a Mao Tse Tung?” (MO)

(06) "Pra ele? Ah, alô amigo, irmão. Normalmente. Oi, mano, mano, chega aqui. Ó, boa noite, boa tarde, tudo bem? Desculpa. Eu tô um bocadinho perdida. Onde é que fica a Mao Tsé Tung? A Mao Tsé Tung fica ali. Ah, obrigada, obrigada. Tchau, tchau. Fica bem. Fica bem. Tá bom. Já tá. (MO)

(07) "Ah, amiguinho. Amiguinho, amiguinho vem cá. Amiguinho, ah, fala lá aí. É essa chapa que vai a Xipamanine? Ah, sim. Ah, tá bom, amiguinho. Obrigada, tá bom, amiguinho. Tá nice. Tenhas um bom dia, tá bom. E muitos, muitos trabalhos pra ti. Ah, ok. Dependendo do que ele estiver a fazer. (MO)

(08) "Ele eu trataria por moço ou como é que dizem? Meu wi $i^{10}$, wi.

Hum hum. O jornal, quanto é que tá o jornal? Quais são, qual é, qual é a principal, qual a notícia destaque dessa semana? E eles dizem normalmente porque,

9. Brada é um tratamento proveniente da palavra inglesa "brother". Mais detalhes acerca dessa FTN serão fornecidos ainda nesta seção.

10. "Wi” é uma expressão comumente utilizada por falantes angolanos para expressar a referência a "amigo, camarada". 
é, os nossos, os ardinas ${ }^{11} \ldots$ hum hum... como, os ardinas gostam de ser tratados de uma forma simpática. Gostam de se sentir à vontade com as pessoas que tão a comprar os jornais. E eu também procuro tentar ser um pouco, ir de acordo com o que ele fala, com o que ele pensa. E chamar de forma informal. Wi. (AN)

Muito embora exemplos solidários produzidos por mulheres em referência a perfis masculinos ocorreram no corpus ora em análise, é difícil estabelecer determinadas generalizações acerca da relação entre usos solidários e gênero. Tudo indica que se trata de uma questão particular à educação, meio social e vivências peculiares a cada informante. Assim, ao se comparar o exemplo 07 com o de número 09 , observam-se direcionamentos completamente opostos acerca do mesmo perfil apresentado. Destaca-se a validade em se comparar esses dois exemplos pelo fato de que foram produzidos por informantes com idades semelhantes (27 e 26 anos), ambas com curso superior completo (uma cientista política e outra psicóloga) e pertencentes a níveis socioeconômicos também compatíveis. Com um intento comparativo, segue o excerto 09 :

(09) "Pra eles, mais uma vez, apesar de estarem não muito longe da minha faixa etária, eu não os chamaria de manos. Porque eles não me parecem assim de muita confiança. Estão assim num chapa e os chapas são assim maningue confusos ${ }^{12}$. E eu também não quero estar a mostrar como é que é mano, não sei quê. Não quero tá a mostrar muitos assuntos. Então eu ia chegar e dizer: por favor, esse chapa vai pro, vai pro Xipamanine? Perguntava assim. Tentava também ser direta, mas não dava também muita confiança.” (MO)

Em linhas gerais, portanto, é válido considerar que os informantes mostraram-se sensíveis aos perfis sociais representados pela fotografias com gênero oposto ao seu no momento de elegerem as FTNs que utilizariam nas simulações de diálogos, tanto em Moçambique quanto em Angola. Acerca de formas utilizadas indistintamente para mulheres e para homens, "brada" teve destaque ao se considerar as entrevistas realizadas nos dois países. Esse tratamento é proveniente da palavra inglesa "brother", mas sofreu um rearranjo em suas características fonético-fonológicas. Assim sendo, além de apresentar-se com diferenças na forma, a palavra "brada" é empregada por falantes dos dois países africanos em referência a interlocutores tanto do sexo masculino quanto do feminino. Dessa forma,

11. "Ardina": em Angola, é o vendedor ambulante de jornais.

12. "Maningue confusos": maningue é uma expressão moçambicana que significa "muito." "Muito confusos", portanto. 
houve um distanciamento da referência masculina original de "brother", mas com a preservação do campo semântico que envolve a noção de "fraternidade" - um uso solidário, portanto, ainda que para desconhecidos. Seguem alguns excertos que ilustram o emprego da FTN "brada", produzidos por uma informante moçambicana de 30 anos, por uma moçambicana de 27 anos e por um angolano de 19 anos, respectivamente:

(12) “É. Olá, como é, brada? Geralmente é assim como se fala aqui em Maputo. Desculpa. Eu gostaria... poderias me ajudar a achar a avenida Amilcar Cabral?" (MO)

(13) “Oi. Tudo bem? Tudo. Ah, aqui também. Pôssas, o calor é que está a matar, hein? Ah, tá tá tá. Sabes aí onde é que vende uma coca, uma cerveja? É ali mesmo. Ixi, ya. Obrigada, ya, brada. Tá nice. Fica bem, hein. Enjoy, aí, o calorzinho! Uma cervejinha. Ah, tá nice. Tá nice. [risos]

Sim. É mesmo informal. É como se eu já lhe conhecesse há muito tempo.” (MO)

(14) "Boa tarde, brada. Eh pá, me indica só onde é que fica, onde é... qual táxi é que eu tenho que apanhar que é pra mim bazar na, no Benfica. Brada ou wi." (AN)

Ao se considerar as respostas de nove informantes moçambicanos que se dirigiram ao perfil social representado pela imagem de uma jovem mulher moçambicana, quatro optaram pela FTN "moça”, três sentiram-se mais à vontade com a ausência de formas de endereçamento e os dois informantes mais jovens (13 e 14 anos) optaram por "tia" e "senhora".

Gráfico 1: Distribuição das FTN

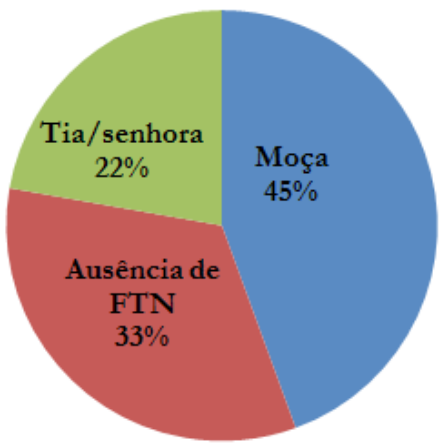

Fonte: Dados da pesquisa 
A FTN "moço (a)" pode ser encontrada em contextos socioculturais muito próximos tanto no Brasil, como em Moçambique e em Angola. Esse termo, cujo sentido original refere-se à qualidade do que é "novo", "fresco"13, disseminou-se entre os falantes como uma FTN mais neutra para se referir a pessoas jovens de ambos os sexos. De forma geral, "moço (a)" é utilizado com referência a desconhecidos, com um sentido pragmático que se estabelece entre a solidariedade e o respeito. Por conta disso, ao se considerar que o perfil social moçambicano em questão aparenta ser jovem, os entrevistados sentiram-se à vontade para chamá-la de "moça", em um indicativo de solidariedade, mas mantendo certa neutralidade, sem parecerem invasivos.

Por sua vez, a ausência de FTN também representa uma escolha pragmática expressiva, haja vista que, nos casos em que os falantes apresentam dúvida ou desconforto em referirem-se ao seu interlocutor por meio de um vocativo, a escolha pela ausência é uma estratégia eficaz de preservação da face. Por último, os dois usos de outros recursos tratamentais como "tia" e "senhora" evidenciaram uma análise do perfil social como sendo hierarquicamente superior ao informante no quesito idade. Em função disso, necessário foi atribuir ao perfil tratamentos representativos de respeito.

Com efeito ilustrativo, é ainda preciso salientar que existe uma tendência de que a FTN "moço(a)" seja primordialmente empregada por mulheres. Na amostra ora em análise, dos quatorze entrevistados angolanos do sexo masculino, oito não utilizaram nenhuma vez essa forma, ao passo que todas as informantes angolanas empregaram ao menos uma vez. Entretanto, essa tendência se altera entre os informantes moçambicanos, uma vez que foram sete mulheres (dentre as 16 informantes) e quatro homens (dentre nove informantes) a não empregarem essa forma.

13. A partir do Novíssimo Dicionário Latino-Português, de Saraiva (2001), "moço" deriva do adjetivo latino "mustus, musta, mustum", que significa "fresco, novo", "vinho por fermentar". Por extensão metafórica, esse adjetivo referia-se à "cordeirinha", ao momento do "frescor da juventude", à "primavera". Autores latinos do período de Ouro usavam "mustum" associado à "moça virgem" (Meus agradecimentos à gentil contribuição de Paulo Veiga). 
Gráfico 02: Uso da FTN “moço(a)” entre entrevistados angolanos e moçambicanos

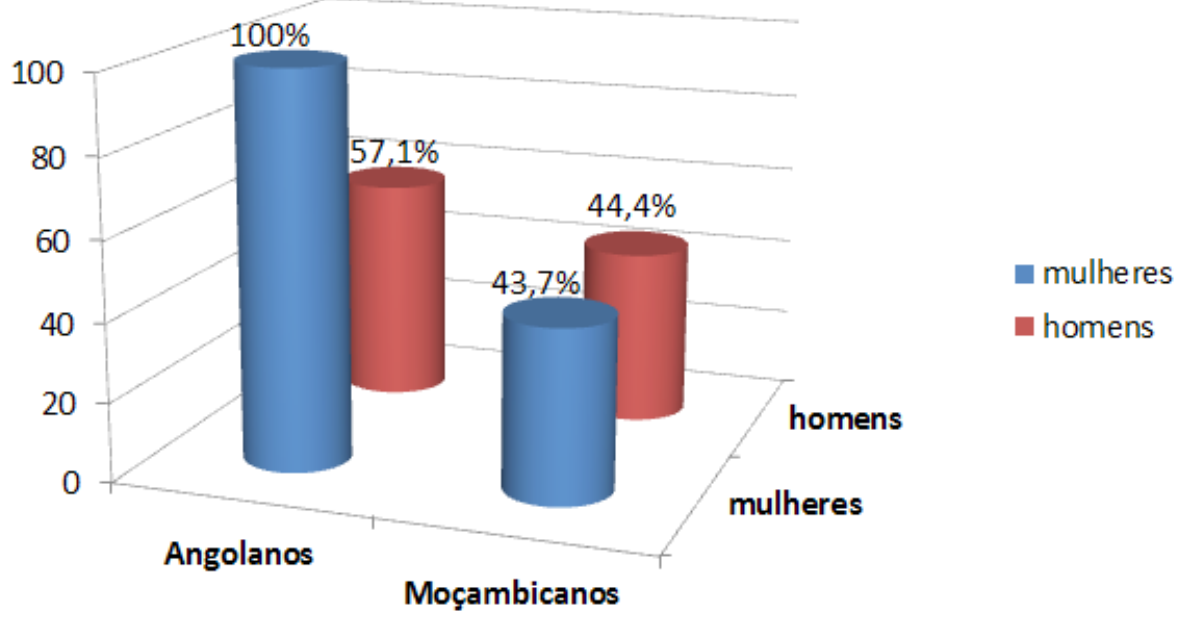

Fonte: Dados da pesquisa

Ainda no que concerne ao tratamento estabelecido entre informantes homens e perfis sociais femininos, um informante de 34 anos fez uma reflexão importante acerca do contexto sociocultural da cidade de Maputo. De acordo com ele, além da questão de gênero, ao se relacionar com mulheres desconhecidas na rua, é preciso estar atento aos preceitos culturais e religiosos por elas adotados. Nesse sentido, ele debate acerca da sua dificuldade em se relacionar com pessoas muçulmanas, uma vez que ele não professa esse credo. Essa discussão pode ser acompanhada no excerto de número 15 com referência à imagem a ele apresentada de duas mulheres trajando vestes muçulmanas:

(15) "Cara, sinceramente? Eu ia escolher outra pessoa pra perguntar.

(É?)

É, porque essas pessoas não se misturam. Se bem que pode chegar e perguntar: ah, faz favor, senhora. Onde, onde é que tem uma mercearia assim? Podia, mas sendo o lugar onde se pudesse optar, eu faria. Não é por nada. É porque eles não se misturam.

(Entendi.)

É, então. Também não ia mexer.

(E eu acho essa uma resposta sim, né. Vai falar com essa pessoa ou não vai? É isso mesmo.)

É. Poderia falar se fosse, mas se tivesse outra pessoa, eu ia falar com a outra. (Tá.) 
Mas por eles mesmo. Não são pessoas abertas a se misturar. Se bem que tu lidas sempre com isto quando vai a lojas deles.

(Isso, isso.)

Né, mas pra passar na rua e eu querer uma informação, se tiver alternativa...

Eu iria perguntar a outra pessoa. Não é por nada. É porque eles. Prontos, também, poderia perguntar. Se fosse homem, talvez. Mas sendo mulher. Essa coisa de muçulmano com mulher.

(Mais complicado.)

É, é, é um pouco.

(Tá.)

Eu já sabendo disso, pô. Então, também manter a distância necessária e segura.

(A distância.)

[risos]

(Entendi.)" (MO)

Para esse informante moçambicano, portanto, a escolha seria não se referir a interlocutoras que se apresentassem com o mesmo perfil identificado pela fotografia. Todavia, se lhe fosse necessário estabelecer um diálogo, a forma escolhida seria "senhora". Essa FTN é pertencente à semântica do poder, por representar a formalidade da interação, ou seja, o reconhecimento de que há um distanciamento hierárquico e/ou cultural entre os interagentes.

Entretanto, a esse respeito, é válido mencionar o comportamento linguístico de um informante angolano de 60 anos, professor universitário da área de humanidades. Dos onze perfis sociais femininos apresentados aos informantes angolanos, esse informante ora em observação empregou três FTNs que se referiam à profissão /ocupação do perfil ("professora", "irmã" e "senhora enfermeira"), uma ausência de tratamento e sete vezes a FTN “minha senhora”. Uma vez que essa tenha sido a sua escolha privilegiada, independente da idade e do status representado pelo perfil, algumas ponderações podem ser feitas. É bem verdade que a forma "senhora" representa o indicativo de distanciamento que esse informante coloca ao se referir aos perfis do sexo oposto - comportamento que se afiniza com a maioria dos informantes homens dos dois países em estudo. No entanto, o pronome possessivo "minha", associado ao tratamento, provoca um efeito de sentido mais solidário e afetuoso por sua característica de associar as pessoas do discurso. Assim sendo, no caso específico desse informante, é possível compreender que, para relações entre gêneros, houve uma estratégia, ao mesmo tempo, respeitosa e cortês (solidária). Com um intento ilustrativo, seguem dois excertos produzidos por esse informante: 
(16) "Muito bom dia, minha senhora. Eu estou aqui e pretendia tratar do cadastramento do meu terreno que tenho lá no Benfica e não sei exatamente em que departamento se trata este assunto. Eu gostaria, por favor, que me ajudasse a localizar o espaço. Seria assim.” (AN)

(17) "Boa tarde, minha senhora. Francamente eu estou a morrer de sede. Conhece por ventura um lugar aqui onde eu possa arranjar uma água ou um sumo? Seria assim." (AN)

Uma vez que tenham sido analisadas as contribuições dos informantes moçambicanos e angolanos no que se refere ao seu repertório de formas de tratamento nominais, é possível afirmar que um dos fatores primordiais que determina escolhas linguísticas é a consideração do gênero da pessoa com quem se estabelece a interlocução. De modo geral, as interações estabelecidas entre pessoas do mesmo gênero nos dois países em análise evidenciaram usos mais solidários, ao passo que entre pessoas de gêneros opostos houve uma maior tendência a escolhas pertencentes à semântica do poder, sobretudo no que concerne a interlocutores com mais idade. Entretanto, conforme verificado, essa tendência não é categórica, haja vista que houve interações entre interlocutores de gêneros diferentes com certa solidariedade entre interagentes mais jovens. Até o momento, verificou-se o comportamento linguístico para as Formas de Tratamento Nominais. A partir de agora, segue-se uma observação sobre a questão do gênero e as escolhas pronominais.

\section{Formas de tratamento pronominais: observando as estratégias sócio- -pragmáticas de mulheres e de homens}

O português moçambicano e o angolano oferecem uma ampla gama de possibilidades de se fazer a referência à segunda pessoa do discurso. São elas: $o$ senhor/ a senhora, $t u$, você, ausência de pronome com desinência verbal de $3^{\mathrm{a}}$ pessoa e ausência de pronome com desinência de $2^{\mathrm{a}}$ pessoa. É válido destacar que a opção linguística privilegiada por falantes desses dois países é a ausência de pronome sujeito, com marcação de pessoa pela desinência verbal. São ilustrativos desses usos:

(18) "Ya. Aí as crianças são um bocado mais sensíveis, né. E eu geralmente o que eu, o que eu faço com criança é olá, fazer uma, uma, uma gracinha, não sei quantos. Olá. Desculpa. Tô, tô à procura do Fulano de X. Conheces? Sabes onde é que ele vive? Não sei quantos." (MO) [Exemplo de ausência de pronome com desinência de $2^{\mathrm{a}} \mathrm{p}$.] 
(19) "Olá, moça. Tudo bem? Podes me dizer se aqui tem um sítio onde vendem gasosa ou água, que eu tô com muita sede." (AN) [Exemplo de ausência de pronome com desinência de $2^{\mathrm{a}} \mathrm{p}$.]

(20) "Pronto, como estamos assim num lugar mais, que não é formal, é praia. Praia que não é formal. Aqui seria: moça, jovem, procuro... podia me indicar onde vende aqui um sumo, um refresco? Não seria tão formal com ela." (MO) [Exemplo de ausência de pronome com desinência de $3^{\mathrm{a}} \mathrm{p}$.]

(21) "Dá um certo medo de dizer ou senhora ou dona porque na verdade nós não sabemos quem é essa pessoa. Poderíamos usar ou senhora ou dona. Mas nós vamos diretamente à pergunta. Boa tarde, por favor, podia explicar onde é que fica...? (AN) [Exemplo de ausência de pronome com desinência de $3^{\mathrm{a}} \mathrm{p}$.]

(22) "Boa tarde, boa tarde. É, eu tô a procura de uma senhora chamada Laurinda, o senhor deve saber quem é, pode me dizer onde é que eu posso encontrá-la?

(Mas agora você chamou de senhor...)

Sim, foi porque já tem uma idade um bocadinho maiores. Já tem, já é... sim. Pode me dizer invés de podes me dizer ou o senhor pode me dizer, acho que fica mais bem educado." (MO) [Exemplo de pronome senhor associado a verbo com desinência de $3^{\mathrm{a}} \mathrm{p}$.]

(23) “Ok. Boa tarde, senhora. É, desculpa o incômodo. É, gostava de poder saber, né, se a senhora podia me explicar onde é que eu podia encontrar isso e aquilo." (AN) [Exemplo de pronome senhora associado a verbo com desinência de $\left.3^{\mathrm{a}} \mathrm{p}.\right]$

A fim de se detalhar a escolha interlocutiva de moçambicanos e de angolanos referente à segunda pessoa, segue a tabela 01 . É válido asseverar que o resultado obtido por meio das entrevistas que formaram o corpus dos dois países é bastante semelhante acerca da questão pronominal. Seguem os dados: 
Tabela 01: Realização pronominal de moçambicanos e angolanos

\begin{tabular}{|c|c|c|c|c|c|c|c|c|c|c|c|c|}
\hline & $\begin{array}{c}\text { Ausência de } \\
\text { pronome + de- } \\
\text { sinência verbal } \\
\text { de } 3^{\text {a pessoa }}\end{array}$ & $\begin{array}{c}\text { Ausência de } \\
\text { pronome + de- } \\
\text { sinência verbal } \\
\text { de } 2^{\mathrm{a}} \text { pessoa }\end{array}$ & \multicolumn{2}{|c|}{$\begin{array}{c}\text { O senhor/ } \\
\text { A senhora }\end{array}$} & \multicolumn{2}{|c|}{ Você } & \multicolumn{3}{|c|}{ Tu } & \multicolumn{3}{c|}{ Total } \\
\hline & $\mathrm{N}$ & $\%$ & $\mathrm{~N}$ & $\%$ & $\mathrm{~N}$ & $\%$ & $\mathrm{~N}$ & $\%$ & $\mathrm{~N}$ & $\%$ & $\mathrm{~N}$ & $\%$ \\
\hline Moçambique & 120 & 48,4 & 53 & 21,4 & 57 & 23 & 10 & 4 & 8 & 3,2 & 248 & 100 \\
\hline Angola & 141 & 60 & 45 & 19,1 & 34 & 14,5 & 10 & 4,3 & 5 & 2,1 & 235 & 100 \\
\hline
\end{tabular}

Fonte: Balsalobre (2015, p.273)

A comparação desses índices permite que se compreenda o sistema linguístico dessas duas variedades africanas como caracterizado por uma morfologia flexional mais produtiva, que leva, consequentemente, a uma menor necessidade de preenchimento do sujeito pronominal. Ainda assim, as dicotomias formal versus informal e poder versus solidariedade são representadas por meio da escolha entre ausência de pronome com desinência verbal de $3^{\text {a }}$ pessoa e $o$ senhor/a senhora, de um lado, e ausência de pronome com desinência de $2^{\mathrm{a}}$ pessoa, tu e você por outro lado. Ao se somar o percentual de sujeito pleno, contudo, Moçambique apresenta um índice de 30,2\% e Angola de 20,9\% (ainda que baixos, esses percentuais não se mostram inexpressivos). Em função dos objetivos presentes - ou seja, a observação da interrelação entre escolhas linguísticas e o gênero do falante -, uma observação importante acerca dos dados moçambicanos precisa ser feita. Com esse intuito, seguem os dados numéricos:

Tabela 02: Realização pronominal por gênero do entrevistado de Moçambique

\begin{tabular}{|c|c|c|c|c|c|c|}
\hline \multirow{2}{*}{ Gênero } & \multicolumn{2}{|c|}{ Ausência de pronome } & \multicolumn{2}{c|}{ Presença de pronome } & \multicolumn{2}{c|}{ Total } \\
\cline { 2 - 7 } & $\mathrm{N}$ & $\%$ & $\mathrm{~N}$ & $\%$ & $\mathrm{~N}$ & $\%$ \\
\hline Mulheres & 128 & 73,1 & 47 & 26,9 & 175 & 70,6 \\
\hline Homens & 45 & 61,6 & 28 & 38,4 & 73 & 29,4 \\
\hline
\end{tabular}

Fonte: Balsalobre, 2015, p.274.

Ao se considerar inicialmente o número absoluto de enunciados, verifica-se que as mulheres moçambicanas produziram muito mais sentenças $(175 / 70,6 \%)$ empregando a estratégia de se dirigir ao interlocutor utilizando alguma referência expressa a ele, seja por meio da realização pronominal, seja pela desinência verbal. Desse modo, infere-se que os homens moçambicanos preferem abordar seu interlocutor restringindo-se ao assunto ${ }^{14}$. Portanto, a maioria dos enunciados

14. A fim de exemplificar essas sentenças em que não ocorre a referência pronominal ao interlocutor, majoritariamente produzidas por homens, segue um excerto: "Boa tarde. Gostaria de saber se o ferryboat já partiu" (MO.F3.08). 
masculinos moçambicanos precisou ser excluída dessa análise em função da não realização de pronomes (ou de referência ao interlocutor por meio da desinência verbal), restando apenas um montante de 73 sentenças, que corresponde a 29,4\% do corpus moçambicano. Ainda assim, em termos percentuais, no que se refere aos enunciados considerados por essa análise - os que contêm pronomes ou desinências verbais indicativas de pessoa -, os homens discretamente favoreceram a ocorrência de preenchimento pronominal de sujeito $(38,4 \%$, contra $26,9 \%$ das mulheres).

A partir dessa reflexão, levanta-se a hipótese de que o fenômeno linguístico em discussão - a ausência ou presença do pronome na posição de sujeito - apresenta valores simbólicos diferentes para moçambicanos e angolanos. Assim sendo, ao se observar os índices de realização pronominal de angolanos, nota-se um equilíbrio entre homens e mulheres $(20,6 \%$ e $21,1 \%$, respectivamente). Seguem os dados:

Tabela 03: Realização pronominal por gênero do entrevistado de Angola

\begin{tabular}{|c|c|c|c|c|c|c|}
\hline \multirow{2}{*}{ Gênero } & \multicolumn{2}{|c|}{ Ausência de pronome } & Presença de pronome & \multicolumn{2}{c|}{ Total } \\
\cline { 2 - 7 } & $\mathrm{N}$ & $\%$ & $\mathrm{~N}$ & $\%$ & $\mathrm{~N}$ & $\%$ \\
\hline Mulheres & 86 & 78,9 & 23 & 21,1 & 126 & 53,6 \\
\hline Homens & 100 & 79,4 & 26 & 20,6 & 109 & 46,4 \\
\hline
\end{tabular}

Fonte: Balsalobre (2015, p.275).

Acerca da relação entre o gênero do entrevistado e a escolha pronominal para se referir à segunda pessoa, é difícil estabelecer uma análise mais concludente acerca dos entrevistados moçambicanos, uma vez que há uma severa disparidade entre o volume de dados de homens e de mulheres, conforme já destacado anteriormente. Já entre os informantes de Angola, novamente é possível observar uma tendência ao equilíbrio entre mulheres e homens para cada uma das possibilidades de realização pronominal permitida pelo sistema. A única exceção evidenciada pela tabela 04 é o fato de que os homens fazem um uso preferencial do pronome você quando comparado às mulheres ( $70 \%$ e $30 \%$, respectivamente) - ainda que o número absoluto de ocorrências seja baixo, essa diferença entre os gêneros pode representar uma tendência. 
Tabela 04: Distribuição de formas pronominais por gênero do entrevistado

\begin{tabular}{|c|c|c|c|c|c|c|c|c|c|c|c|c|}
\hline \multirow[t]{2}{*}{ País } & \multirow[t]{2}{*}{ Gênero } & \multicolumn{2}{|c|}{$\begin{array}{c}\text { Ausência de } \\
\text { pronome }+ \\
\text { desinência } \\
\text { verbal de } 3^{\text {a }} \\
\text { pessoa }\end{array}$} & \multicolumn{2}{|c|}{$\begin{array}{l}\text { O senhor/ } \\
\text { A senhora }\end{array}$} & \multicolumn{2}{|c|}{$\begin{array}{c}\text { Ausência de } \\
\text { pronome }+ \\
\text { desinência } \\
\text { verbal de } 2^{\text {a }} \\
\text { pessoa }\end{array}$} & \multicolumn{2}{|c|}{$\mathrm{Tu}$} & \multicolumn{2}{|c|}{ Você } & \multirow[t]{2}{*}{ Total } \\
\hline & & $\mathrm{N}$ & $\%$ & $\mathrm{~N}$ & $\%$ & $\mathrm{~N}$ & $\%$ & $\mathrm{~N}$ & $\%$ & $\mathrm{~N}$ & $\%$ & \\
\hline \multirow{2}{*}{ Moçambique } & Mulher & 85 & 48,5 & 36 & 20,5 & 43 & 24,5 & 7 & 4 & 4 & 2,2 & 175 \\
\hline & Homem & 35 & 47,9 & 21 & 28,7 & 10 & 12,6 & 1 & 1,3 & 6 & 8,2 & 73 \\
\hline \multirow{2}{*}{ Angola } & Mulher & 67 & 61,4 & 18 & 16,5 & 19 & 17,4 & 2 & 1,8 & 3 & 2,7 & 109 \\
\hline & Homem & 74 & 58,7 & 16 & 12,6 & 26 & 20,6 & 3 & 2,3 & 7 & 5,5 & 126 \\
\hline
\end{tabular}

Fonte: Balsalobre (2015, p.278)

É também importante observar que a combinação entre os vocativos e os pronomes que exercem a função de sujeito, ou a ausência deles, considera o gênero do entrevistado e a observação dos perfis sociais como um elemento de caráter social e pragmático que interfere em sua composição. Assim sendo, ao se analisar esse aspecto em Angola, observa-se que os padrões de comportamento entre os homens e mulheres são mais próximos. Em termos gerais, todos os informantes apresentaram índices muito semelhantes para três possibilidades combinatórias: vocativo de poder e desinência verbal de $3^{\text {a }}$ pessoa; vocativo de solidariedade e desinência de $3^{\mathrm{a}}$ pessoa; e ausência de vocativo. Esses índices são expressos por meio da tabela 05 e exemplificados pelos excertos de 24 a 26 :

Tabela 05: Principais possibilidades combinatórias entre vocativos e pronomes sujeito por gênero do entrevistado no corpus angolano

\begin{tabular}{|c|c|c|c|c|}
\hline \multirow{2}{*}{ Relação entre o vocativo e o pronome (ou desinência verbal) } & \multicolumn{3}{|c|}{ Gênero do entrevistado } \\
\cline { 2 - 5 } & \multicolumn{2}{|c|}{ Feminino } & \multicolumn{3}{|c|}{ Masculino } \\
\cline { 2 - 5 } & $\mathrm{N}$ & $\%$ & $\mathrm{~N}$ & $\%$ \\
\hline Vocativo = poder / Ausência de pronome + des. verbal de 3 $\mathrm{p}$. & 34 & 31,1 & 33 & 26,1 \\
\hline Vocativo = solidariedade / Ausência de pronome + des. verbal de 3 $\mathrm{p}$. & 19 & 17,4 & 28 & 22,2 \\
\hline Ausência de vocativo & 27 & 24,7 & 26 & 20,6 \\
\hline
\end{tabular}

Fonte: Balsalobre (2015, p.302)

24) Relação entre um vocativo pertencente ao eixo semântico do poder e a ausência de um pronome sujeito com desinências verbal de $3^{\mathrm{a}}$ pessoa. É exemplo: "Boa tarde, senhor. Desculpa, será que podia me informar ou me dizer onde é que eu posso pegar o táxi?" (AN) 
25) Relação entre um vocativo pertencente ao eixo semântico da solidariedade e a ausência de um pronome sujeito com desinências verbal de $3^{\text {a }}$ pessoa. É exemplo: "Olá, minha linda. Tudo bom? Sabe onde eu posso comprar uma água?” (AN)

26) Ausência de vocativo - que, portanto, não permite comparação com o pronome. É exemplo: "Tudo bem? Conheces um menino que chama-se Luis? Assim pequenino, magrinho." (AN)

Assim como ocorreu no caso das formas de tratamento nominais, para os tratamentos pronominais o gênero do perfil social representado por meio de fotografias revelou-se determinante para a escolha linguística dos entrevistados. A fim de demonstrar a relevância do fator gênero, mais detidamente serão observados os comportamentos linguísticos de informantes moçambicanos e angolanos quando expostos a imagens de mulheres jovens.

Entre os moçambicanos, das doze mulheres que simularam diálogo com essa imagem apresentada, empregando formas pronominais ou desinências verbais com marca pessoal, onze delas dirigiram-se ao perfil por meio de estratégias informais. Já entre os homens, das sete respostas válidas, cinco empreenderam estratégias pronominais mais formais. Em algumas respostas masculinas, houve inclusive menção à informalidade do contexto em que o perfil se encontrava associado a vocativos solidários, mas a desinência verbal mantinha distanciamento. Para se ilustrar esses casos, seguem excertos moçambicanos - o de número 27 foi produzido de uma maneira mais informal por uma mulher de 50 anos e o 28 por um homem de 43 anos:

(27) "Oi moça. Sabes onde fica o quiosque mais próximo? Tamos todas, quer dizer, num ambiente informal, não é?” (MO)

(28) "Pronto, como estamos assim num lugar mais, que não é formal, é praia. Praia que não é formal. Aqui seria: moça, jovem, procuro... podia me indicar onde vende aqui um sumo, um refresco? Não seria tão formal com ela.” (MO)

Exemplo como o de número 27 também é encontrado em Angola. Esses casos sugerem que, ainda que haja uma combinação semântica entre a forma de tratamento nominal e o pronome - ou a ausência pronominal com marcação de pessoa por meio da flexão verbal - eles podem indicar uma gradação de formalidade, em que a forma nominal carrega um valor mais marcado, seja em direção ao poder 
ou à solidariedade, em função de seu conteúdo lexical expresso, e o pronome indicia valores um pouco menos marcados também nas duas direções possíveis. Para ilustrar esse fato, com referência ao corpus angolano, segue o excerto 29, produzido por um homem de 26 anos:

(29) "Mas como ela está com um sorriso lindo, eu não vou chegar pra ela tão frio e formal: olá, minha linda. Tudo bom? Sabe onde eu posso comprar uma água? Eu tô cheio de sede." (AN)

\section{Palavras finais}

Conforme a expectativa inicial, o sistema de formas de tratamento empregado por moçambicanos e angolanos revelou-se assaz pertinente para o estudo dessas variedades de língua portuguesa, cujo foco é a inter-relação existente entre língua e sociedade. De um modo geral, a questão do gênero mostrou-se um fator motivador importante para a opção por uma forma de tratamento em detrimento de outras. Em linhas gerais, as mulheres preferem tratar homens desconhecidos com mais reserva e distanciamento, ao passo que os homens também mantêm interações com mulheres de uma forma mais distanciada.

Assim, a partir dos informantes dos dois países, é possível identificar que há mais solidariedade entre pessoas desconhecidas do mesmo gênero. Ainda acerca do gênero dos informantes, Angola apresentou uma peculiaridade. Os informantes desse país não apresentaram diferenças significativas no que se refere ao preenchimento pronominal do sujeito, enquanto que os informantes homens de Moçambique foram os que favoreceram esse uso. Entre os moçambicanos, por sua vez, foi nítida a diferença no padrão de comportamento entre homens e mulheres quanto à forma de se abordar o interlocutor: majoritariamente, as mulheres fazem perguntas, ao abordar desconhecidos, empregando algum tipo de referência a essa $2^{\mathrm{a}}$ pessoa, seja por meio de um pronome, seja por meio da flexão verbal indicativa de pessoa. Já os homens, preferem estratégias mais diretas, contemplando apenas o assunto de seu interesse, sem referência ao interlocutor.

Entre os moçambicanos, homens e mulheres, "evitar vocativo" foi o recurso mais utilizado ao dirigirem-se aos seus interlocutores, em uma estratégia de preservação da face, já que assim, evitam descortesias e constrangimentos. No entanto, evitar vocativo não foi a estratégia mais utilizada pelos angolanos, em um indicativo de que se dirigir ao outro predicando ou evitando a predicação não apresenta a mesma representação simbólica para todos os povos. Assim, cada nação encontra suas próprias estratégias para preservarem a sua face em interações linguísticas. 


\section{Referências}

Abreu, Maria Teresa dos Santos, Mercer, José Luiz da Veiga. O tratamento em Curitiba: o pronome zero. Revista Ilha do Desterro. A Journal of English Language, Literatures in English and Cultural Studies, Florianópolis, n. 20, 1988.

Atlas de Moçambique. Maputo: Editora Nacional de Moçambique, 2009.

Balsalobre, Sabrina Rodrigues Garcia. Brasil, Moçambique e Angola: desvendando relações sociolinguísticas pelo prisma das formas de tratamento. 2015. 345p. Tese (Doutorado em Linguística e Língua Portuguesa). Faculdade de Ciências e Letras, Universidade Estadual Paulista (UNESP), Araraquara, 2015.

Brown, Roger; Gilman, Albert. The pronouns of power and solidarity. In: Giglioli, Pier Paolo. (Ed.) Language and social context: selected readings. Michigan: Peguin Books, 1972 [1960]. p.252-281.

Dias, Hildizina. As desigualdades sociolinguísticas e o fracasso escolar: em direção a uma prática linguístico-escolar libertadora. Maputo: Promédia, 2002.

Firmino, Gregório. A questão linguística na África pós-colonial: o caso do português e das línguas autóctones em Moçambique. Maputo: Texto editores, 2006.

Firmino, Gregório. A nativização do português em Moçambique. In.: Carvalho, Clara. Cabral, João de Pina (Org.). A persistência da história: passado e contemporaneidade em África. Lisboa: Imprensa de Ciências Sociais, 2004.

Fonseca, Dagoberto José. Nas marolas do Atlântico: interpretações de Angola, da África, do Brasil e de Portugal. Relatório Científico de Pós-Doutorado apresentado ao Departamento de Ciências Sociais na Educação da Faculdade de Educação da Universidade de Campinas, Campinas, 2009.

Giaufret, Anna. De Mário a Otário. As formas de tratamento nominais: modelos de função alocutiva ou predicativa. In: Couto, Letícia Rebollo, Lopes, Célia Regina dos Santos. (Org.) As formas de tratamento em português e em espanhol: variação, mudança e funções conversacionais. Niterói: Editora da UFF, 2011. p.47-60.

Kerbrat-Orecchioni, Catherine. Modelos de variação intraculturais e interculturais: as formas de tratamento nominais em francês. In: Couto, Letícia Rebollo, Lopes, Célia Regina dos Santos. (Org.). As formas de tratamento em português e em espanhol: variação, mudança e funções conversacionais. Niterói: Editora da UFF, 2011. p.19-46.

Labov, William. Padrões sociolinguísticos. Tradução Marcos Bagno, Maria Marta Pereira Scherre, Caroline Rodrigues Cardoso. São Paulo: Parábola Editorial, 2008 [1972].

Levinson, Stephen. Pragmatics. Nova Iorque: Cambridge University Press, 1989.

Levinson, Stephen. Pragmática. Tradução Luís Carlos Borges, Aníbal Mari. São Paulo: Martins Fontes, 2007.

Lopes, Célia Regina dos, Rumeu, Márcia Cristina de Brito. Marcotulio, Leonardo Lennertz. $\mathrm{O}$ tratamento em bilhetes amorosos no início do século XX: do condicionamento estrutural ao 
sociopragmático. In: Couto, Letícia Rebollo, Lopes, Célia Regina dos Santos (Org.). As formas de tratamento em português e em espanhol: variação, mudança e funções conversacionais. Niterói: Editora da UFF, 2011. p.321-354.

Marcotulio, Leonardo Lennertz. Língua e História: o $2^{\circ}$ marquês de Lavradio e as estratégias linguísticas no Brasil Colonial. Rio de Janeiro: Ítaca, 2010.

Paiva, Maria da Conceição. A variável gênero/sexo. In.: Mollica, Maria Cecília, Braga, Maria Luiza. (Org.) Introdução à sociolinguística: o tratamento da variação. São Paulo: Contexto, 2013. p.33-42.

Paredes e Silva, Vera Lúcia. A variação você/tu na fala carioca. Comunicação apresentada no $1^{\circ}$ Encontro de variação linguística do Cone Sul, UFGRS, 1996.

Mundim, Sônia Sandra de Moura. Formas de tratamento e vocativos no Rio de Janeiro. Dissertação de mestrado em Linguística. Universidade Federal do Rio de Janeiro, 1981.

Neto, Muamba Garcia. Aproximação linguística e experiência comunicacional: o caso da escola de formação Garcia Neto. Luanda: Editora Mayamba, 2012.

Neves, Maria Helena de Moura. Os pronomes. In: Ilari, Rodolfo, Neves, Maria Helena de Moura (Org.). Gramática do português culto falado no Brasil. Vol.2. Campinas: Editora da UNICAMP, 2008. p.507-622.

Saraiva, Francisco dos Santos. Novíssimo diccionario latino-portuguez. Rio de Janeiro: Garnier, 2001.

Vidal, Victoria Escandell. Introducción a la pragmática. Barcelona: Editorial Ariel, 1996. 